\title{
Social and Behavioural Science Teaching in Medicine and Public Health in India
}

\author{
N. Nakkeeran ${ }^{1}$, Kavya Sharma ${ }^{2}$, Sanjay P. Zodpey ${ }^{2}$
}

\begin{abstract}
The importance of social determinants on health has been consistently highlighted in public health debates. However, this has not been the case in the sphere of medical or public health education. This review paper aims to discuss the status and problems associated with teaching social and behavioural sciences in medicine and public health programs in India. A country like India requires a medical / public health manpower that is responsive to social reality and sensitive to the role of social determinants in shaping health and health-inequity. Although social and behavioural sciences form a part of the curriculum in undergraduate and postgraduate medical, public health and health management programs, the space made available for such are limited. The problem rests on the institutional structures through which these programs are offered and on issues such as the way medicine is practiced vis-à-vis the patient and overriding emphasis on doctors in professional hierarchy in public health practice and research. In most medical institutions social and behavioural sciences (SBSs) are taught by people with no formal training in these disciplines. Correspondingly, the priority given to students is too low. Absence of efforts to make a tangible connection between social science learning and medical / public health practice, lack of well-defined career opportunities and professional dominance of mainstream medical disciplines over others are some of the reasons for this low priority. Problems also reside in the degree of heterogeneity in content, vastness of scope, diversity in perspectives within each discipline, and a lack of standardized curriculum and reading materials.
\end{abstract}

Key words: social sciences, preventive and social medicine

\section{Introduction}

The long drawn debate on the questionable contribution of medicine in improving human health may stand unsettled but it nevertheless underwrote the crucial role of non-medical factors in shaping health or lack of it of a population (Colgrove, 2002; Link \& Phelan, 2002). The importance of social determinants of health has been consistently highlighted in public health debates and policy arena.

\footnotetext{
${ }^{1}$ Associate Professor, Indian Institute of Public Health Gandhinagar, Gujarat, India

${ }^{2}$ Public Health Foundation of India, Vasant Kunj, New Delhi, India
}

Corresponding Author: N. Nakkeeran,

Associate Professor, Indian Institute of Public Health Gandhinagar, Ahmedabad - 380054, Gujarat, India.

E-mail: nnakkeeran@gmail.com
The signing of the Millennium Development Goals in 2000 and the formation of Commission on Social Determinants of Health (CSDH) signified a renewed emphasis on social determinants of health: "the devastating health inequities we see globally are manmade. The causes are social - so must be the solutions" (CSDH, 2007, p.3).

Michael Marmot, one of the principal architects behind the Commission has noted that "treating existing disease is urgent and will always receive high priority but should not be to the exclusion of taking action on the underlying social determinants of health" (2005).

This importance accorded in the policy sphere however, has not been reflected meaningfully in medical education globally. Within medical and public health schools the space available for SBSs is very limited. A recent analysis notes that "across the globe, behavioural 
science in medicine is losing its place and its identity" and there is a "need to defend the importance of behavioural sciences as a valid and important area of medicine and to justify its inclusion in curricula to both colleagues and to students" (Chur-Hansen et al., 2008). A lack of scope to contribute, behavioural science subjects being taught by medical professionals having no formal training in the subject, insignificant space in the curricula, a preeminence to the bio-medical paradigm and construing medicine as a problem based knowledge have been highlighted as some of the important issues that pose a problem to behavioural scientists in a medical setting (Chur-Hansen et al., 2008). SBSs not only has a legitimate place in medicine and public health but also a responsibility towards articulating alternative paradigms of explanations for health and health inequity across individuals and populations. This review paper aims to discuss the role, status and problems associated with SBSs teaching in medicine and public health in India.

\section{Social and behaviour sciences: issues of definition and perspectives}

In mainstream social and behavioural sciences schools different disciplines maintain independent existence and identity. This is a necessity given the sharp differences in terms of content, theory, methodology and pedagogy. Though there are overlaps and continuities between disciplines at some junctures there are also numerous irreconcilable differences in methodologies and perspectives. Each of these disciplines sociology, anthropology, psychology, history economics, political science, philosophy, geography etc. have autonomous grounds to genuinely inter-phase with the field of public health. Each individual discipline has carved out its exclusive niches in the form of 'medical anthropology', 'medical sociology', 'health psychology', 'health economics' etc.

However, within public health, at one level, instead of acknowledging an independent existence of these disciplines a common space is accorded through a rubric such as 'Social and Behavioural Sciences'. The original flavours of independent disciplines have been coalesced into one. SBSs teaching within public health has evolved as a product of these complexities with a wide range of variations in content, scope, emphasis, and methodologies. Furthermore, the overall importance enjoyed by SBSs vis-à-vis other disciplines within public health too has varied across various schools of public health.

In recent decades a number of public health schools have come up in the country with SBSs forming an integral part of the public health curriculum. However, there are no common guidelines or curricula for teaching SBSs. Across different schools it is taught from divergent perspectives: while there is a close overlap with public health in some schools, in others it is taught purely as a political discourse.

Across public health programs, when social and behavioural sciences are taught as a skill based course it is taught divorced of its criticality as well as its local relevance. For instance, in the Indian context, issues such as patriarchy, caste, landlessness, poverty etc. are either not discussed or touched upon (MUHS, n.d; National Board of Examinations, 2005). On the other hand when it is taught as a perspective building course it identifies both problems and solutions as systemic in nature. In this perspective the course remains at the critique level of the system from a political economic perspective (Jawaharlal Nehru University, n.d).

\section{Lack of priority among students}

With the explosion of knowledge in biomedical sciences and with technological innovation SBSs is not anymore just a 'nice to know' aspect of medical education but is now a 'need to know' aspect (MacLeod \& McCullough, 1994; Peters \& Litvia, 2006). However, for reasons such as uncertain relevance for clinical practice, incongruity between social science knowledge and biomedical models, illdefined educational goals, lack of wellestablished curricula, absence of teaching materials and shortage of adequately qualified teachers, medical students have traditionally shown a lack of interest in learning social and behavioural sciences (Benbassat, 1996; Isaac \& Rief, 2009).

One of the reasons why SBSs have failed to gather sufficient importance in Indian medical education is the way medical practice happens in most similar situations in India. Patientcentred issues such as care, dignity, meaning of illnesses and understanding them are often kept out of the purview of medical treatment in modern medical settings. In developed countries the general practitioners (GPs) take care of the aspects concerning patient-centred care (Unger et al., 2003). In a country like 
India, neither the GPs nor the nursing staff are oriented towards patient-centred care. On the other hand, access to healthcare and inequity continue to remain major concerns, requiring a discussion on economic and political issues which are far removed from the medical domain. A strong hierarchy within the medical profession with pre-eminence to doctors and insufficient professionalization of lower level health personnel such as nursing staff could be another problem.

\section{Institutional structures}

In terms of institutional structures SBSs are taught in undergraduate and selected post graduate medical, public health and health / hospital management curricula. During the undergraduate medical course students' exposure to SBSs is limited to the course on preventive and social medicine (PSM). For many reasons this course receives the least priority from students (Benbassat, 1996; Isaac \& Rief, 2009). SBSs content in selected MD and DNB programs is significantly more important than in the undergraduate medical course. These postgraduate students also get exposed to issues related to SBSs during the internship.

One of the stated objectives of the MD in PSM / CM or Diploma in Public Health (DPH) / Diploma in Community Medicine (DCM) is to identify the socio-cultural dimensions of health and disease and apply this knowledge in the designing and implementation of public health and development programs. In line with this objective the course curriculum includes principles and concepts in SBSs including sociology, anthropology, psychology as well as health economics and application of these aspects in public health and development. In addition, the curriculum also focuses on SBSs issues in specialized sub-fields such as social issues in nutrition, social measures in genetics, industrial psychology, social paediatrics, social determinants such as housing, sanitation, and occupation and allied themes such as demography, health care of disadvantaged groups including tribal, the aged, and people with disabilities, role of voluntary sector in health and qualitative research (Medical Council of India, n.d).

The preamble written by the Diplomate of National Board (DNB) in its new regulations for DNB in Family Medicine points out that "to practice holistic medicine, the treating physician should also understand the social, cultural and economic conditions of the family" and defines Family Medicine "as that specialty of medicine which is concerned with providing comprehensive care to individuals and families and integrating biomedical, behavioural and social sciences" (NBE, 2005). The program specifically has "behavioural and social sciences related to family medicine' as a content area. The program encourages the ability to provide care in community settings, engage with the community to harness available community services and to effectively communicate with patients and the community (NBE, 2005).

However, at both undergraduate and postgraduate levels, courses on social and behavioural sciences are exclusively taught by faculty members with medical qualifications and not necessarily by those with training in social or behavioural sciences. As per the existing rules of recruitment no social or behavioural science personnel are eligible to be recruited as a faculty member in a medical college. Current guidelines of $\mathrm{MCl}$ state that non-medical teachers are allowed only in departments of anatomy, physiology, biochemistry, pharmacology and microbiology (MCl, 1998)

\section{Masters in Public Health}

Compared to MBBS and MD programs, the SBSs component is relatively more significant in the Masters Programs in Public Health, Health Administration, and Community Health. The two year program usually covers courses on introduction to SBSs, social epidemiology, Indian society including women and gender issues, health services and community. In addition, students may also follow basic or foundation courses and elective courses such as women and health, urban health, health planning and health economics, workers health, role of NGOs in health care etc. (Tata Institute of Social Sciences, n.d; JNU, n.d).

Unlike overseas universities, no Indian university has SBSs as a concentration in $\mathrm{MPH}$. MPH in social epidemiology is offered by the Tata Institute of Social Sciences (TISS), which focuses on providing a conceptual understanding of public health issues.

It has specific modules on SBSs such as understanding society, social science perspective on health, basic economics and health economics, social and behavioural influences on health as well as qualitative research methods (Tata Institute of Social Sciences, n.d). 


\section{Health and Hospital Management Education}

Over 50 institutes in the country offer postgraduate training in health or hospital management related courses (Sharma \& Zodpey, 2010). They are offered as MD, MBA, and MHA or as a Diploma depending upon the location of the institution in medical, management or social science schools. These programs have not only an exclusive paper on SBSs, but also a number of other papers which require a SBS perspective such as women and gender issues, health economics, health promotion, health and development and qualitative research methods. SBSs content varies depending on the location of the course: whether in a medical institution or outside.

In addition there are possibilities of M.Phil or Doctoral degrees that are awarded from public health departments in social science schools or individual scholars working on public health topics from general SBSs departments. In these programmes the SBSs content is of a higher level with options to choose topics and courses on specific sub-disciplines such as medical anthropology, medical sociology, health psychology, health economics or even an exploration in health from the disciplines such as history and political science.

\section{Professional associations and activism}

We have also seen the emergence of associations such as Indian Association of Social Sciences in Health (IASSH), IndiaClen and Medico Friends Circle (MFC), which bring together social scientists, medical and public health professionals.

\section{Conclusion}

In the foregoing pages we have attempted to draw the attention of public health and medical educationists to SBSs in public health and medical education. Rapid urbanization, globalization, aging populations, persistent poverty, reemerging infections and increased role of social environment in shaping the burden of NCDs have forced the importance of social determinants of health. However in medical and public health education SBSs teaching is yet to come of age. The problem rests on the institutional structures through which medical and public health education is offered and on a number of other issues such as the way medicine is practiced, overriding dominance of doctors in professional hierarchy etc. In addition, problems also reside in the degree of heterogeneity in content, vastness of scope and diversity in perspectives professed by different SBSs as well as different schools of thought within each discipline. The intersection between medicine and public health and SBSs is not all clearly defined. Unlike medical and public health disciplines which are founded on a more or less coherent epistemology based on biomedical paradigm, the diverse SBSs stand for a range of paradigmatically different epistemologies: from a pure positivist to constructionist, post-modernist etc. As a result, even within a discipline, there are multitudes of definitions, explanations and theories for each concept or problem. While this is in fact an essential strength of SBSs it becomes a limitation when this situation interfaces with medical and public health learning at undergraduate and postgraduate levels. Lack of standardized curricula, books and other reading materials is also a problem. Lack of priority among students towards SBSs is another problem that was discussed. Absence of efforts to make a tangible connection between social science learning and medical/public health practice, lack of welldefined career opportunities for aspirants coming out of medical/public health with SBSs as a track and professional dominance of mainstream medical disciplines over others are some of the reasons.

Medical/public health manpower should be responsive to social reality and sensitive to the role of social determinants in shaping health and health-inequity. A medical and public health education that gives to students a sound base in SBSs is crucial. An earnest attempt on the part of medical and public health educationists as well as social scientists to address some of the issues discussed in the foregoing pages is an imperative.

\section{References}

Benbassat, J. (1996) Teaching the social sciences to undergraduate medical students, Israel Journal of Medical Sciences, 32, 3-4, pp. 217221.

Chur-Hansen, A., Carr J.E., Bundy, C., SanchezSosa, J.J., Tapanya, S. \& Wahass, S.H. (2008) An international perspective on behavioural science education in medical schools, Journal of Clinical Psychology in Medical Settings, 15, 1, pp. $45-53$.

Colgrove, J. (2002) The McKeown thesis: A historical controversy and its enduring influence, American Journal of Public Health, 92, 5, pp. 725-729. 
Commission on Social Determinants of Health (CSDH) (2007) Achieving health equity: From root causes to fair outcomes: Interim Statement, CSDH, World Health Organization, Geneva.

Isaac, M. \& Rief, W. (2009) Role of behavioral and social sciences in medical education, Current Opinion in Psychiatry, 22, 2, pp. 184-187.

Jawaharlal Nehru University (n.d) Centre of Social Medicine and Community Health [online] available at: http://www.jnu.ac.in/Academics /Schools/SchoolOfSocialSciences/MedicineCent er.htm [Accessed on 07 July 2011]

Link, B.G. \& Phelan, J.C. (2002) McKeown and the idea that social conditions are fundamental causes of disease, American Journal of Public Health, 9, 5, pp. 730-732.

MacLeod, S.M. \& McCullough, H.N. (1994) Social science education as a component of medical training, Social Science Medicine, 39, 9, pp. 1367-1373.

Maharashtra University of Health Sciences (n.d) Curriculum of M.D. in Community Medicine, MUHN [online] available at: http://www. muhsnashik.com/syllabus/PG_Syllabus/ Community_Medicine_MD.pdf [accessed 16 May 2011].

Marmot, M. (2005) Social determinants of health inequalities, Lancet, 365, pp. 1099-1104.

Medical Council of India (MCI), (1998) Medical Council of India Minimum Qualifications for Teachers in Medical Institutions Regulations, (amended up to November, 2010) [online] available at: $h$ ttp://www.mciindia.org/rules-andregulation /Teachers-Eligibility-QualificationsRgulations-1998.pdf [Accessed on 05 Aug 2011].
Medical Council of India (MCl) (n.d) [online] available at: $h t t p: / / w w w . m c i i n d i a . o r g / I n f o r m a t i o n$ Desk/CollegesCoursesSearch.aspx? $N=82$ [Accessed on 07 July 2011]

National Board of Examination (2005) DNB in Family Medicine (New Regulations) [online] available at: http://www.natboard.edu.in/ notice_board/notice_file/Curriculum_for_DNB Family_Medicine New_Rules_ UPDATE.pdf [Accessed on 16 May 2011].

Peters, S. \& Litvia, A. (2006) Relevant behavioral and social science for medical undergraduates: a comparison of specialist and non-specialist educators, Medical Education, 40, 10, pp. 10201026.

Sharma, K. \& Zodpey, S.P. (2010) Need and opportunities for health management education in India, Indian Journal of Public Health, 54, 2, pp. 84-91.

Tata Institute of Social Science, (n.d) Information Brochure for Master's Degree Program 20112013, TISS: Mumbai [online] available at: http://www.tiss.edu/tiss-attachements/ downloads/m.a.-information-brochure [Accessed on 07 July 2011].

Unger, J.P., Paepe P. De. \& Green, A. (2003) A code of best practice for disease control programmes to avoid damaging health care services in developing countries, International Journal of Health Planning and Management, 18, pp. S27-S39. 